\title{
"EU LEIO ASSIM ESTE LIVRO": LEITURA DE UMA TRILOGIA DE REBELDES
}

\author{
Maria Lúcia Wiltshire de Oliveira \\ (Universidade Federal Fluminense)
}

Três vazios; leitura de Geografia de rebeldes de Maria Gabriela Llansol

Lisboa, Ed.Vendaval, 2009

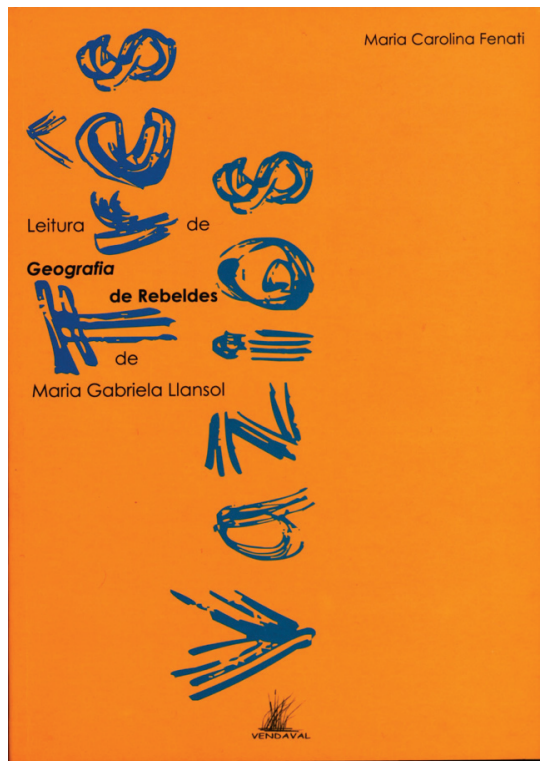

Releio no título do ensaio de Carolina Fenati - Três vazios; leitura de Geografia de rebeldes de Maria Gabriela Llansol (Lisboa, Ed.Vendaval, 2009) - a reiterada palavra do pórtico de O livro das comunidades a serviço de uma leitura que percorre a trilogia inaugural da escritora, cuja produção (re)principia ${ }^{1}$ sob o signo do vazio. Não se trata apenas de uma chave de interpretação, mas de uma verruma que penetra o texto fazendo-o falar segundo o nosso modo mais habitual de escutar. O texto ensaístico nos inicia na obra por meio de vozes teóricas e críticas que explicitam o sentido de uma escrita que se funda no vazio e dele faz a sua matéria, acrescida da voz da ensaísta que, com muito zelo e propriedade, apresenta posições e anteposições. Numa discussão bem encadeada entre capítulos e itens, a autora apresenta-nos a essência dessa trilogia-manifesto que marca a nova e definitiva dicção assinada por Llansol, que é a autonomização da escrita frente a gêneros, a modelos narrativos, a intencionalidades autorais e a idiossincrasias literárias. Ao se utilizar metodologicamente dos três vazios para desdobrar a sua análise, a ensaísta consegue tratar dos principais aspectos que fizeram de Llansol uma escritora ímpar no cenário da narrati- 
va portuguesa contemporânea pós-25 de Abril, já tão pródiga de grandes nomes. Mais do que analisar o "enredo" dos livros, o ensaio se dedica a colher os traços distintivos da escrita como uma Paisagem (termo de Llansol) onde se podem ler o Vazio Provocado, o Vazio Continuado e o Vazio Vislumbrado, que denotam uma outra realidade narrativa - uma guerra dos perdedores - e se aplicam respectivamente aos três livros do conjunto.

A bem dizer, as obras desta trilogia formam um conjunto homogêneo comprovado por muitas razões, a começar pela continuidade textual que se observa entre o fim de uma e o início da outra. Como vemos na última página de O livro das comunidades, concluído em 1974 e publicado em 1977, Llansol lançou uma ponte com o anúncio do "novo ser" - "Era o fim do texto, mas fim provisório. Recomeçou na manhã seguinte o diálogo com o novo ser, diálogo mudo constituído por olhares, carícias, ausências, pensamentos, sorrisos e medo" (LLANSOL, 1977, p. 87), que na página inicial de $A$ restante vida é a figura decapitada de Thomas Münster: "o novo ser era um monstro" (LLANSOL, 1982, p. 11). Do mesmo modo, no fim deste livro, diz o texto llansoliano que "Ana de Peñalosa estava na casa de Julho e Agosto aguardando a aproximação desse mar" por onde "seus hóspedes, de rara presença, haviam de vir" (LLANSOL, 1982, p. 95) para habitar o novo livro, Na casa de Julho e Agosto (1984), que começa com Luís M., figura tradicionalmente associada ao mar e ao Tejo.

A abordagem dos temas ao longo do ensaio se ajusta aos três vazios que metem medo. Ao primeiro medo, o Vazio Provocado, que se refere à indefinição do humano ou ao seu caráter mutante, a ensaísta articula a análise das figuras rebeldes que habitam aquela singular geo-grafia; ao segundo medo, o do Vazio Continuado e relativo a uma Tradição não-oficial, chamada "da Restante vida", faz corresponder a observação dos rebeldes como exemplos alternativos de singularidades, com destaque para o processo de purificação de São João da Cruz; por fim, ao medo do Vazio Vislumbrado, centrado no corp' a’screver, o ensaio estabelece conexão com o processo da escrita que passa pelo olhar (com discussão sobre a imagem), pela palavra (com questionamento da arte e da literatura), pelo tempo (com o tratamento do devir como simultaneidade) e pelo corpo que escreve (com debates sobre a autoria).

As análises da primeira e da terceira parte são mais desdobradas do que as da segunda parte dedicada ao Vazio Continuado; não obstante, esta última apresenta um dos pontos altos do ensaio, subintitulado "Noite obscura", onde é feita a discussão acerca da figura de São João da Cruz que "expõe-se à metamorfose, metamorfose do seu corpo e dos seus livros, no forno a assar, sua carne liberando cheiros ao passar pelo imprevisível da noite obscura" (FENATI, 2009, p. 68). À semelhança de outros rebeldes, a figura do místico do século XVI revela a sua própria singularidade, trazida como própria à linhagem dos poetas que também são alimentados pela noite e pela obscuridade ${ }^{2}$.

Há ainda mais dois pontos relevantes no ensaio: o primeiro é a discussão do sentido de comunidade em que fica clara a afirmação da dissemelhança, e não da identidade, a compor estes grupos, de que a própria obra da autora portuguesa é um exemplo; o segundo é a abertura de um debate sobre o conceito de imagem em Llansol, que deve merecer desenvolvimento em futuros ensaios críticos sobre a obra. Destacam-se também 
o tratamento das diferenças entre narratividade e textualidade que sustenta o primeiro capítulo, e o aproveitamento dos conceitos teóricos expostos no início e ao longo do trabalho. As ideias de pensadores chamados "difíceis", como Blanchot, Deleuze, Foucault, Barthes, Agamben e outros, são manejadas de modo a "traduzir" os procedimentos llansolianos em linguagem acadêmica, o que dá ao ensaio um perfil oportuno para uso didático. $\mathrm{Na}$ mesma direção seguem as referências à fortuna crítica da trilogia pela consulta a ensaístas consagrados, como Silvina Rodrigues Lopes, João Barrento, Maria Etelvina Santos e Pedro Eiras que, entre outros, dão credibilidade e coerência à leitura empreendida, harmonizando o viés de análise com a linha teórica assumida. Merecem destaque as notas de rodapé que enriquecem a leitura do texto, ao mesmo tempo em que preservam o padrão escorreito do ensaio.

Ainda que tenha o mérito de tratar a trilogia como um todo, o estudo não aprofunda a visão de cada um dos livros em particular, nem estabelece relações mais estreitas entre eles relativamente às suas semelhanças e dissemelhanças. Se não era este o propósito do trabalho, fica ao menos assentada a possibilidade de sua complementação em estudos que possam dar destaque à tessitura dos "lugares" da primeira obra (O livro das comunidades) ou às partes e aos capítulos das obras seguintes (A restante vida $\mathrm{e}$ Casa de julho e agosto).

Ao adentrar a análise do pórtico de O livro das comunidades, que lhe serve de leitmotiv e base metodológica, a ensaísta não arriscou uma leitura que tirasse da obscuridade algumas passagens assinadas pelo enigmático alter ego llansoliano A. Borges que assina o prólogo. Por exemplo, se o livro é a "Tradição segundo o espírito da Restante Vida", por que esta é "uma razão para não o tomarmos a sério" (LLANSOL, 1977, p. 10)? Como compreender "um corpo Cem Memórias de Paisagem" em que os homófonos "cem" e "sem" se mesclam e se distinguem? Por fim, considerando que o projeto literário de Llansol enfrenta a questão do vazio, como explicar as duas obscuras linhas que fecham o pórtico: "Quem há que suporte o Vazio?/ Talvez Ninguém, nem Livro.” (LLANSOL, 1977, p. 10).

O que fica deste estudo é a convicção de que o texto de Llansol, apesar de aparentemente difícil, é acessível graças às penetrações e atravessamentos da ensaísta que é legente, no sentido que deu Llansol a esta palavra, ou seja, aquele que não toma o texto "nem por ficção, nem por verdade, mas por caminho transitável” (EIRAS apud FENATI, 2010, p. 13), tornando-o igualmente transitável para os leitores do seu ensaio. Segundo apuramos, o texto decorre de uma pesquisa de mestrado realizada pela autora na Universidade Nova de Lisboa, contemplado com a publicação por mérito pela Direcção Geral do Livro e das Bibliotecas. Efetivamente é um estudo que alicia e inicia leitores no fascinante mundo imagético de Llansol e, como leitura dos três tempos do Vazio, é "o seu rastro - desejando que assim possa surgir uma oferta de palavras, um modo de partilhá-las marcado pela inquietação, pelo medo e pela alegria" (FENATI, 2010, p. 112). Maria Carolina assim lê estes três livros, contornando o medo com a alegria de um "inacabamento", convocando outros legentes que podem e devem começar sua leitura por esta trilogia, a considerar o que diz Maria Gabriela Llansol num manuscrito inédito de 1981: "Se um livro pudesse pendurar-se, como um quadro, sobre a chaminé, eu escolheria O Livro das comunidades." (Cad.1-10, p. 287) 


\section{NOTAS}

1 Com esta obra inaugura-se uma narratividade que rompe com a prosa anterior publicada anos antes: Os Pregos na Erva (1962) e Depois de Os Pregos na Erva (1973).

2 Lembro aqui a divisa de um personagem-poeta de Herberto Helder pendurada na parede em frente a sua cama: "Meu Deus, faz com que eu seja sempre um poeta obscuro" (HELDER, 1985, p. 172)

\section{REFERÊNCIAS BIBLIOGRÁFICAS}

FENATI, Maria Carolina. Três vazios; leitura de Geografia de rebeldes de Maria Gabriela Llansol. Lisboa: Vendaval, 2009.

HELDER, Herberto. Os passos em volta 5ª ed. Lisboa: Assírio e Alvim, 1985.

LLANSOL, Maria Gabriela. A casa de julho e agosto. Lisboa: Afrontamento, 1984. . Espólio Llansol, Caderno 1-10 (inédito).

. O livro das comunidades. Lisboa: Afrontamento, 1977. . A restante vida. Lisboa: Afrontamento, 1982.

(Recebido para publicação em 3/11/2010

Aprovado em 7/12/2010) 